\title{
Assessment of WHO ten steps towards successful breastfeeding among postpartum mothers in Karaikal: A hospital based cross-sectional study
}

\author{
Farhan', Sarthak Das², Archana Malik ${ }^{3}$ \\ ${ }^{1}$ MBBS Student, Jawaharlal Institute of Postgraduate Medical Education and Research(JIPMER), ${ }^{2}$ Assistant Professor, \\ Department of Paediatrics, ${ }^{3}$ Senior Resident, Department of Pulmonary Medicine, Jawaharlal Institute of Postgraduate \\ Medical Education and Research(JIPMER), Karaikal, Puducherry, India
}

\section{A B S TR A C T}

Background: Breastfeeding is the most essential, dynamic and profitable method of giving infants the perfect start in life. The Recent Rapid Survey on Children in India shows that $44.6 \%$ infants are now being breastfed within an hour of birth and $64.9 \%$ of $0-6$ months old infants were exclusively breastfed. Aims and Objectives: To estimate the proportion of mothers who successfully breastfeed their children according to the WHO ten steps towards successful breastfeeding. Materials and Methods: A Cross-sectional study was conducted in Postpartum ward of JIPMER, Karaikal from $1^{\text {st }}$ August to $31^{\text {st }}$ September. Mothers aged 18- 49 years; given birth to healthy, singleton baby and stayed in hospital for minimum 24 hours after delivery were included in the study. The questions about breastfeeding practices based on "WHO ten steps of successful breastfeeding" were asked. Mothers knew seven steps or more(score $\geq 7$ ) were considered as having successful breastfeeding. Results: Out of 205 only $32(15.60 \%)$ mothers breastfeed their child successfully. There is significant difference between multiparous and primiparous mothers in Breastfeeding initiation within one hour of delivery $(p=0.04)$ and Prelacteal feeding Practice $(p=0.003)$. The successful breastfeeding rate was higher among multiparous compared to primiparous mothers which is statistically significant $(p=0.032)$. Conclusion: There is existence offaulty practice in breastfeeding process among post-partum mothers. The role of health professionals in encouraging optimal breastfeeding are remarkably low. Compulsory Implementation of BFHI in every hospitalby a Breastfeeding Committee, can be planned to increasing the breastfeeding rate.

Key words: Baby friendly hospital initiative; Postpartum mothers; Southern India; Successful breastfeeding.

\section{INTRODUCTION}

Breastfeeding is a natural event; this performance is an accomplished practice that requires continuous effective support to make it successful. Breastmilk is the most superior feed for the infant to fulfil the nutritional need for proper growth and development of the infant. ${ }^{1}$ Breastfeeding has both short term benefits like protection from respiratory infections and diarrheaas well as long term benefits on blood sugar level, Intelligence and obesity.,
Breastfeeding practiceshave a positive impact on the infant mortality rate in the developing countries like India. ${ }^{4}$ As per latest Lancet Breastfeeding Series, exclusive breastfeeding can prevent $32 \%$ of all respiratory infections, $54 \%$ of all cases of diarrhea and $87 \%$ of deaths of infants less than 6 months of age. ${ }^{5}$

The global breastfeeding score card by WHO and UNICEF which evaluated 194 nations show that only $45 \%$ of the mothers initiate breastfeeding within one hour of 
delivery while there are only 23 countries with exclusive breastfeeding rates being above $60 \%$.' In India, the Recent Rapid Survey on Children(RSOC) shows that only 44.6\% infants are now being breastfed within an hour of birth and only $64.9 \%$ of $0-6$ months old infants were exclusively breastfed $^{7}$. In 2014Ministry of Health \& Family Welfare has prepared India New-born Action Plan (INAP) to reach the target of $75 \%$ and $90 \%$ rate of initiation of breastfeeding within an hour of birth by 2017 and 2025 respectively. ${ }^{8}$

The Baby-friendly Hospital Initiative (BFHI) was launched by WHO and UNICEF in 1991 and underwent revision in 2004-2006, introduces 'Ten steps to successful breastfeeding' as the Intervention to encourage breastfeeding practices to decrease the infant mortality rate(IMR). ${ }^{9}$ In India, BFHI was initiated in 1993, and studies show an increased rate of early initiation of breastfeeding in Baby Friendly Hospitals compared to non-BF hospitals. ${ }^{10}$ the current progression rate will not reach the target of "early breastfeeding initiation rate" and so, research on implementation of the 10 steps to successful breastfeeding is required which would provide a base for further progress towards reaching the target as per INAP.

Hence an attempt was made to assess the maternal practices about WHO ten steps to successful breastfeeding among post-partum mothers.

\section{MATERIALS AND METHODS}

A Hospital based Cross-sectional study was conducted inPost partum ward of JIPMER, Karaikal a newly teaching hospital from $1^{\text {st }}$ August to $31^{\text {st }}$ September 2017. The proportion of mothers who adhere to WHO ten steps for breastfeeding to their children was $23.5 \%$, with confidence Interval of $95 \%$ and $5 \%$ absolute precision, the estimated sample size was 205.Mothers aged 18- 49 years; given birth to healthy, singleton baby and stayed in hospital for minimum 24 hours after delivery were included in the study.Mothers who underwent any immediate postpartum complication, landed in emergency or didn't consent,mothers who gave birth to babies with any congenital abnormality or babies that required admission in neonatal unit for any medical reason were excluded from study.

\section{Data collection}

After getting approval by Institutional Ethical committee, patients were enrolled in the study with proper informed consent. The first section of questionnaire consisted of questions on demographic profile of mothers (age, Parity, education, occupation, socioeconomic status, family type, mode of delivery and baby (gender, weight). The second section contained close ended questions (Yes/No) about breastfeeding method based on "WHO ten steps of successful breastfeeding". ${ }^{13}$ Mothers knew seven steps or more(score $\geq 7$ ) were considered as having successful breastfeeding. ${ }^{13}$

\section{Statistical analysis}

The data obtained from the study was entered in Excel sheet andanalyzed using SPSS 20.0 (IBM Corporation, New York, and U.S.A) software. The various clinical parameters recorded were summarized using mean/ median (continuous data) and proportions (binary data). Continuous variables with normal distribution were compared using student $t$ test and those not normally distributed using Mann Whitney test. Chi square test or Fisher test was used for analyzing categorical variables. A multivariate logistic regression analysis has done to predict the independent variables that affecting the final outcome (successful breastfeeding)among postpartum mothers with successful breastfeeding. All statistics were two-tailed, and a $\mathrm{P}<0.05$ was considered to be significant.

\section{RESULTS}

Total 205 postpartum mothers were interviewed after qualifying the inclusion criteria. The mean age of the mothers was $25.97 \pm 0.50 y$ ears. Demographic profile of mothers mentioned in Table: 1.

Among babies, $122(59.5 \%)$ and 83(40.5\%) were male and females respectively. The mean weight of babies was $2.80 \pm 0.500 \mathrm{~kg}$. Our study showed neither there was written breastfeeding policies displayed on the walls of department nor the mothers were aware of it (Step-1). The healthcare staffs gave support for breastfeeding to only $129(62.92 \%)$ mothers during their stay in hospital and $76(37.08 \%)$ mothers did not get any support(Step-2).Only 106 (51.7\%) mothers were educated by health professionals regarding breastfeeding importance during pregnancy and $99(48.3 \%)$ did not have any interaction with trained healthcare staffs (Step-3). Breastfeeding started within one hour of birth by 113(55.13 \%) mothers in hospital while 92(44.87\%) started late(Step-4). One hundred and forty three $(69.8 \%)$ mothers were not taught by healthcare staffs how to express breastmilk and $62(30.2 \%)$ mothers got the demonstration (Step-5). Hundred and five $(75.60 \%)$ mothers confined to only breastmilk as the infant feed and $50(24.40 \%)$ mothers had started formula milk with breastfeeding during hospital stay(Step-6). Rooming in was not practiced by $105(51.2 \%)$ mothers(Step-7). Our Study showed only $82(40 \%)$ mothers breastfed their child on a demand basis while the 123(60\%) mothers breastfeed on specific interval basis (Step-8). Maximum mothers $187(91.20 \%)$ did not use pacifiers while it was used by only $18(8.80 \%)$ mothers during hospital stay(Step-9). Majority of 
mothers 193 (94.10\%) were not aware about breastfeeding support groups while only 12(5.90) mothers contacted breastfeeding support groups during requirement (Step10). Percentage of observance of WHO ten steps towards successful breastfeeding is provided in descending order (Table:2)

The final outcome of the study showed that only $32(15.60 \%)$ mothers (score $\geq 7$ ) breastfeed their child successfully according to the 10 steps to successful breastfeeding by WHO (Figure. 1)

At the time of analysis, stratification was done to control effect modifiers. Post-stratification, Chi-square test was applied.

\begin{tabular}{|c|c|c|}
\hline Variable & Categories & Frequency (\%) \\
\hline \multicolumn{3}{|c|}{ Occupation } \\
\hline & House wife & $197(96.1)$ \\
\hline & Employed & $8(3.9)$ \\
\hline \multicolumn{3}{|c|}{ Educational Status } \\
\hline & Nil & $4(2)$ \\
\hline & Primary & $7(3.4)$ \\
\hline & Inter & $92(44.9)$ \\
\hline & Matric & $25(12.2)$ \\
\hline & Graduate & $73(35.6)$ \\
\hline & Higher & $4(2)$ \\
\hline \multicolumn{3}{|l|}{ Parity } \\
\hline & Primigravida & $94(45.9)$ \\
\hline & Multigravida & $111(54.1)$ \\
\hline \multicolumn{3}{|c|}{ Family Type } \\
\hline & Joint & $131(63.9)$ \\
\hline & Nuclear & $74(36.1)$ \\
\hline
\end{tabular}

\begin{tabular}{|c|c|c|}
\hline Step No. & $\begin{array}{l}\text { Steps of successful } \\
\text { breastfeeding }\end{array}$ & Frequencies $\mathrm{n}(\%)$ \\
\hline 10 & $\begin{array}{l}\text { Breastfeeding } \\
\text { support groups }\end{array}$ & 193(94.10) \\
\hline 9 & $\begin{array}{l}\text { No use of dummies/ } \\
\text { pacifiers }\end{array}$ & $187(91.2)$ \\
\hline 6 & $\begin{array}{l}\text { Child fed with only } \\
\text { human milk (no } \\
\text { supplement use) }\end{array}$ & $105(75.6)$ \\
\hline 2 & $\begin{array}{l}\text { Support of trained } \\
\text { staff }\end{array}$ & $143(62.92)$ \\
\hline 4 & $\begin{array}{l}\text { Initiation of } \\
\text { breastfeeding within } \\
\text { one hour }\end{array}$ & $113(55.13)$ \\
\hline 3 & Prenatal education & $106(51.7)$ \\
\hline 7 & Rooming in & $100(48.8)$ \\
\hline 8 & $\begin{array}{l}\text { On demand } \\
\text { breastfeeding }\end{array}$ & $82(40)$ \\
\hline 5 & $\begin{array}{l}\text { Teaching of how to } \\
\text { express breast milk }\end{array}$ & $62(30.2)$ \\
\hline 1 & Written policy & $0(0)$ \\
\hline
\end{tabular}

Breastfeeding initiation within one hour of delivery is practiced more by multiparous mothers $68(60.17 \%)$ than primiparous $45(39.83 \%)$ which was statistically significant $(\mathrm{P}=0.04)$. Initiation of breastfeeding within half hour of delivery was also compared between family type (joint verses nuclear) $(\mathrm{P}=0.415)$ and employment status of mother, which were statistically insignificant $(\mathrm{P}=0.716)$.

There was significant difference in Prelacteal feeding between multiparous mothers 28 (56\%) andprimiparous mothers $22(44 \%)(\mathrm{P}=0.003)$. Prelacteal feeding by mothers in accordance to employment status of mother $(\mathrm{P}=0.400)$, type of family $(\mathrm{P}=0.200)$ and gender of the baby $(\mathrm{P}=0.750)$ were not statistically significant.

The success rate for breastfeeding was higher among multiparous mothers 17 (56.67\%) when compared to $13(43.33 \%)$ primiparous mothers which was significant $(\mathrm{p}=0.032)$.

The comparison for successful breastfeeding between employment status of mother $(p=0.400)$, educational status of mothers and type of family $(p=0.220)$ were all statistically insignificant.

There was no significant change in the success rate of breastfeeding based on gender $(\mathrm{p}=0.480)$ and weight $(p=0.060)$ of the baby delivered.

\section{DISCUSSION}

WHO recommended ten steps to successful breastfeeding in 1991 to promote breastfeeding rate which has been implemented globally in more than 152 countries. ${ }^{11}$ The ten steps to successful breastfeeding are the basis of Baby friendly hospital initiative (BFHI) which is approved by Americanacademy of paediatrics (AAP). ${ }^{11} \mathrm{WHO}$ recommends occurrence of child birth in maternity facility care, but hospital policy does not necessarily promote

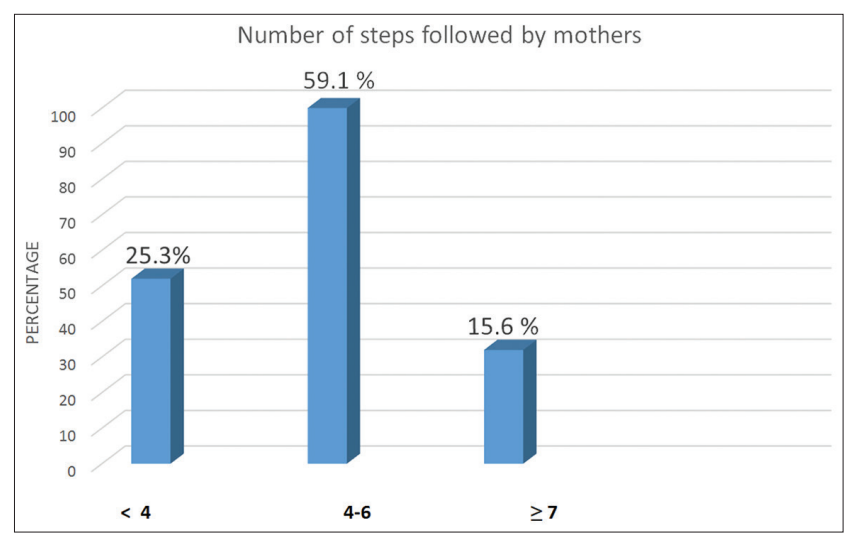

Figure: 1 Observance of successful breastfeeding by mothers 
the breastfeeding practice. ${ }^{2}$ Initiation of breastfeeding occurring in maternity facility care needs a supportive environment to facilitate breastfeeding rate among postpartum mothers. ${ }^{11}$ So all the health care staffs in hospital are required to be trained and become skillful to make a conducive environment for favorable breastfeeding practices and a written policy mentioning "ten steps to successful breastfeeding" is essential for certified a hospital as baby friendly hospital. All post-partum mothers require motivation and continuous support from health professionals as well as from family members for successful breastfeeding.

Our study mentioned there is no written policy specifying WHO ten steps to successful breastfeeding which is similar to a study done in Brazil. ${ }^{12}$ But $63.5 \%$ mothers have read and understood breastfeeding policy displayed on hospitalwalls by a study in Pakistan. ${ }^{13}$ This difference may be due to various practice adopted by different hospitals in different region.

In evaluation of step two by us, $62.9 \%$ mothers were supported by healthcare personnel during postpartum period which is nearly similar toa study in rural Pakistan $(69.2 \%) .{ }^{13}$ Doctors supported $81.03 \%$ mothers for breastfeeding in hospital as per study in Gujrat. ${ }^{14}$ Another study in India found that nurses did not give advice about breastfeed to mother rather she has advised to give ghutti which is like honey. ${ }^{15}$ This disparity is probably due to different level of awareness and training among health care staffs about WHO ten steps to successful breastfeeding.

Only $51.7 \%$ of mothers were counselled regarding breastfeeding during pregnancy as per step three evaluation. During antenatal visit $35.1 \%$ and $63.77 \%$ mothers were discussed with health professionals related to breastfeeding management in rural and urban Pakistan respectively. ${ }^{13,16}$ Majority of the hospitals reported $92.8 \%$ antenatal mothers were educated about breastfeeding management during hospital visits in the United States. ${ }^{17}$ This difference between developed and developing country can be explained by different degree of hospital practices, availability of trained health professionals and literacy rate of mothers for assessing and understanding problems related to breastfeeding.

Initiation of breastfeeding within one hour of delivery was observed in $55.1 \%$ of mothers as per our study which is better than current rapid survey $44.6 \%$ by Government of India. ${ }^{7}$

Only $30.2 \%$ mothers were taught the technique of breastfeeding by hospital staffs in our study which is similar to study (35.1\%) in Pakistan, but in developed countrieslike
United States, 89.1\% mothers got demonstration for breastfeeding techniques in hospital. ${ }^{17}$ This disparity could be explained by the variety of policies adopted by developing and developed countries.

Majority of mothers (75.6\%) fed only breastmilk andrest gave pre-lacteal feed which is totally opposite to study in Pakistan where feeding confined to breast milk was observed in $29.1 \%$ of mothers only, rest had given prelacteal feed along with breastmilk. ${ }^{13}$ pre-lacteal feed was practiced in $46.1 \%$ among Gujarati mothers and 32\% among Saudi mothers. ${ }^{14,18}$

According to our study more than half of mothers (51.2\%) were neither practicing nor aware of rooming in but $94.6 \%$ Pakistani mothers and $72 \%$ Saudi mothers practiced the methods. ${ }^{11,18}$ This is due to the fact that newborns are taken care of by other family members after feeding time which was revealed by the mothers during interview in our study.

Demand basis feeding was seen among $40 \%$ of mothers in our study, which is very less as compared to study in Pakistan (85.8\%), Bangladesh (96\%) and Iran (64.6\%). ${ }^{19,20}$ This is due to lack of awareness on breastfeeding benefits among postpartum mothers.

Our study revealed that $91.2 \%$ mothers did not use any dummies or pacifiers during breastfeeding which is similar that $97.3 \%$ among Pakistani mothers. ${ }^{20}$

Our hospital there is no special breastfeeding support group but only $5.4 \%$ post-partum mothers contacted any attended healthcare staffs specially doctors and nurses at the time of requirement which is very similar to study in Pakistan (7.4\%). ${ }^{11}$ But in developed country like U.S and Brazil, breastfeeding support groups were contacted by $26.8 \%$ and $66.6 \%$ post-partum mothers respectively. ${ }^{17,12}$

Finally, successful breastfeeding was observed in $32(15.60$ $\%)$ mothers who scored $\geq 7$ according to WHO ten steps to successful breastfeeding in our study where as $\geq 7$ score was found by $23.70 \%$ Pakistani mothers. ${ }^{13}$

Initiation of breastfeeding was compared between the parity status of mother in which multiparous mothers performed better than the primiparous $(\mathrm{p}=0.04)$ which is similar to the study in Pakistan $(\mathrm{p}=0.04) .{ }^{13}$

Overall, in our study there was no statistical association of educational status, employment status, family type with successful breastfeeding which is similar to other study by developing country except parital status. ${ }^{13}$ Sex, weight of child did not show any significant association with successful breastfeeding which is similar to our study. ${ }^{13}$ 
Limitations of the study

The limitations of the study that it is a single centered and cross sectional study. The study is first attempt in this region to study all about WHO ten steps of successful breastfeeding.

\section{CONCLUSION}

There is existence of extensive disparity from knowledgeto-practice in breastfeeding process among mothers, mostly due to paucity of knowledge regarding beneficial effect of the recommended breastfeeding practices, the hazardous consequence of not following the recommended steps and how to practice them. The role of health professionals in encouraging and augmenting optimal breastfeeding are remarkably low. Unavailability of written breastfeeding policy, delayed initiation of breastfeeding, feeding not given on demand basis and bad breastfeeding practices among primiparous mothers are the major concern. it is suggested for creation of a Breastfeeding Committee, formandatory implementation of BFHI in hospital and finally increasing the breastfeeding rate.

\section{ACKNOWLEDGEMENT}

Dr. Ramya, Senior Resident, Department of Community Medicine, JIPMER,Karaikal for her technical assistance

\section{REFERENCES}

1. AnatolitouF. Human milk benefits and breastfeeding,Journal of Pediatric and Neonatal Individualized Medicine 2012;1(1):11-18.

2. Short-term effects of breastfeeding: a systematic review on the benefits of breastfeeding on diarrhoea and pneumonia mortality. World Health Organization ISBN 9789241506120 (NLM classification: WS 125)

3. Short-term effects of breastfeeding: a systematic review on the benefits of breastfeeding on diarrhoea and pneumonia mortality. World Health Organization ISBN 9789241506120 (NLM classification: WS 125)

4. Huffman SL, Zehner ER and Victora C. Can Improvements in Breast-Feeding Practices Reduce Neonatal Mortality in Developing Countries? Midwifery Journal 2001;17:(20):80-92.

5. Rollins N, Bhandari N, Hajeebhoy N, Horton S, Lutter C, Martines J, et al. Why invest, and what it will take to improve breastfeeding practices?. The Lancet. 2016;387(10017):491-504.
6. Global breastfeeding collective,Global breastfeeding scorecard,Tracking Progress for Breastfeeding Policies and Programmes 2017

7. Ministry of Women and Child Development (MWCD), Government of India. Rapid Survey on Children (RSOC) 20132014. Factsheets. MWCD, 2015

8. Indian National Action Plan (INAP), Ministry of health and family welfare, Government of India (2014)

9. BABY-FRIENDLY HOSPITAL INITIATIVE Revised, Updated and Expanded for Integrated Care. ISBN 9789241594967 (v. 1) (NLM classification: WQ 27.1)

10. Report of All India Study of Newborn Care, Infant Feeding Practices and Implementation of the "Infant Milk Substitutes, Infant Foods and Feeding Bottles (Regulation of Production, Distribution and Supply) Act, 1992." In the Hospital Settings, and Infant Feeding Practices in the Catchment Area of These Hospitals.

11. MeekJY and Noble L. Implementation of the Ten Steps to Successful Breastfeeding Saves Lives. JAMA Pediatr 2016; 170(10):925-926.

12. Soraia L, Mariana L, Cândida $P$ and Franciéle M. Baby-Friendly Hospital Initiative: evaluation of the Ten Steps to Successful Breastfeeding, Rev Paul Pediatr 2013;31(4):488-493.

13. Masood S, Mahmood-ur-Rahman, Mahmood H, Faisal T, Maroof $S$ and Qureshi AM. Observance of who ten steps towards successful breastfeeding; a survey from postpartum mothers, J Ayub Med Coll Abbottabad 2016;28(1):84-88.

14. Chaudhry AG, Ahmed A, Hussain $S$, Ali $N$ andBatool $A$. Ananthropological study of breastfeeding practices and prevalence of supported liquids among child-bearing women in rural Gujrat. Science International 2014;ISSN:1013-5316. 26. 483-487

15. Lingam R, Gupta P, Zafar S, Hill Z, Yousafzai A, lyengar S, et al. Understanding care and feeding practices: building blocks for a sustainable intervention in India and Pakistan. Ann N Y 2014;1308:204-217.

16. Hanif R, Khalil E, Sheikh A, Harji A, Haris S, Rasheed MW, et al. Knowledge about breastfeeding in accordance with the national policy among doctors, paramedics and mothers in baby-friendly hospitals. J Pak Med Assoc 2010;60(10):881-886.

17. Centers for Disease Control and Prevention (CDC). Vital signs: hospital practices to support breastfeeding - United States, 2007 and 2009. MMWR Morb Mortal Wkly Rep 2011;60:1020-1025.

18. El Gilany A, Sarraf B and AI Wehady A. Factors associated with timely initiation of breastfeeding in Al-Hassa province, Saudi Arabia, East Mediterr Health J2012;18(3):250-254.

19. Haider R, Rasheed S, Sanghvi TG, Hassan N, Pachon H, Islam $\mathrm{S}$, et al. Breastfeeding in infancy: identifying the programrelevant issues in Bangladesh. Int Breastfeed J 2010;5:21.

20. AbdulAmeer A, Al Hadi AH and Abdulla MM. Knowledge, attitudes and practices of Iraqi mothers and family childcaring women regarding breastfeeding. East MediterrHealthJ 2008;14(5):1003-1014.

\footnotetext{
Authors Contribution:

F-Concept and design of study, review literature, data collection, manuscript preparation; SD-Concept and design of study, data analysis and interpretation, critical review the study and manuscript, drafted the manuscript; AM-Conceptualized study, data collection,literature search,data analysis,manuscript preparation

\section{Work attributed}

Department of Paediatrics, JIPMER, Karaikal, India.

Orcid ID:

Farhan- (i) https://orcid.org/0000-0002-6446-8425

Dr. Sarthak Das- (D) https://orcid.org/0000-0003-2013-8173

Dr. Archana Malik- (i) https://orcid.org/0000-0001-8507-3353

Source of Support: Nil, Conflict of Interest: None.
} 